\title{
Adolescent Girls' Knowledge and Attitude About Mental Health Issues: A Questionnaire
}

\author{
Prasenjit Ray ${ }^{1 *}$, Amrita Chakraborti ${ }^{3}$, Amit Kumar Bhattacharyya ${ }^{4}$, Paramita Ray $^{4}$ and Asim Kumar Mallick ${ }^{2}$ \\ ${ }^{1}$ RMO cum Clinical Tutor, Burdwan Medical College, India
}

${ }^{2}$ Professor, Burdwan Medical College, India

${ }^{3}$ RMO cum Clinical Tutor, Diamond Harbour Medical College, India

${ }^{4}$ Professor, Institute of Mental Health, Kolkata

Received: 眥 August 29, 2018; Published: 眥 September 06, 2018

*Corresponding author: Prasenjit Ray, Burdwan Medical College, India

\begin{abstract}
Background: The aims of this current study were to prepare and validate a Bengali questionnaire to assess knowledge and attitude of adolescents about the various mental health issues related to them, and to conduct a pilot study with this questionnaire.

Method: It was a cross sectional study conducted on adolescent school girls ( $N=107,12$ to 18years age) from rural background of West Bengal. A 13 item Bengali questionnaire was constructed, validated and administered on the subjects. Statistical analysis was done using SPSS (16th version).

Results: Most of the items had good test re-test reliability. Mean age of the population was 13.09 years. Three knowledgebased questions had more correct responses $(50.5 \%, 52.3 \%, 50.5 \%)$ and one had $72 \%$ incorrect responses. Majority of the subjects recognised problem behaviours, expressed a helping attitude, tended to seek help from parents, and thought sharing worries with others and spending time with friends could make them happy.

Conclusions: This questionnaire appears reliable to assess knowledge and attitude of adolescent girls. There is need to inform adolescents about various mental health issues. Attitude to help and a sense of cohesion was conspicuous in this population. A larger and more inclusive study needed to generalize the findings.
\end{abstract}

Keywords: Adolescents; Awareness; Reliability

\section{Background}

Adolescence and its crisis have been object of amazement and awe since ages. With the recent rise of the instances of problem behaviour like self-harm, criminal acts and various risk taking acts by adolescents, especially in our country, it has become necessary to look into the problem through an adolescents'-lens, to know about how much aware they are about the phenomenon of transformation from a child to an adult, about the various changes, challenges and problems typical of this period [1]. Part of this transition is a plethora of changes pertaining to the manner they view the things around them, about others, about themselves. Often these changes become too much for them to cope up with, resulting in various mental health issues like adjustment problems, depression, and self-harm behaviors [2]. At times problems such as pervasive unhappiness and depression, quarrelling, using abusive language and delinquent behaviour in school students, especially at secondary level, have been found to be posing serious threat to proper academic and personality development of the students [3]. Owing to a number of factors like, the different developmental trajectories for boys and girls, explained by the negative experience of intensification of stereotypical gender roles and differences in pubertal development resulting in earlier maturity of girls leading to apparent differences in processes of family influence, girls during adolescence have a typical pattern of disclosing their inner world and spending time alone or with peers and parents which is distinct from the boys in adolescence [4,5]. These, along with cultural practices, often result in problems like excessive anxiety, depression, feelings of low self-esteem, avoidant behavior and excessive dependence on others, more in adolescent girls [6]. 
To face the challenges of this critical period, to cope up with the crises and to deal effectively with others with those problems one need to be aware about those issues [7]. Inspite of the fact that, gathering information about their awareness of mental wellbeing and their attitude towards mental health problems forms a critical step for behavioral scientists to intervene into those situations, Little attention has been focused on promoting mental health awareness, especially in less economically developed nations where the burden is great $[8,9]$. Studies have suggested that direct targeting of children themselves is ideal for increasing awareness $[7,10,11]$. As part of 'Adolescence Health Training Program', a joint venture of Sarva Shiksha Mission (Dept. of School Education, Govt. of West Bengal) and Burdwan Science Centre (National Council of Science Museums, Ministry of Culture, Govt. of India), adolescent girls from different schools (class 6 to 10) were brought, in batches, in a convention centre of Burdwan (a town in West Bengal) to be addressed about the different problems of adolescence. They attended lectures by Psychiatrists and Gynecologists on different aspects of adolescents' problems. To assess their awareness about mental health a questionnaire was needed. After searching literature, several questionnaires were found that assesses the problems and problem behaviors of adolescents, though not much was found that assesses the knowledge and attitude of adolescents about the mental health issues that are so particular of their age. This dearth seemed to be more glaring when the target population was adolescent girls coming from rural parts of West Bengal. So, one questionnaire was devised by the research team, with input from concerned persons, with the purpose of assessing adolescents' knowledge and attitude pertaining to certain common mental health issues of their age. Before using this questionnaire in larger perspective, it was needed to validate this tool and to undertake one pilot study. This pilot study was conducted as a forerunner of another bigger study targeting around 1000-2000 adolescents meant to explore various mental health issues of that age group to formulate plans to help them cope up with those problems more effectively.

Aim

The aims of this current study were:

a. To prepare a Bengali questionnaire to assess knowledge and attitude of adolescents about the various mental health issues related to adolescence and validate it.

b. To conduct a pilot study with this questionnaire on adolescent school girls from rural background of West Bengal.

\section{Method}

a. It was a cross sectional study conducted on 107 adolescent school girls from rural background of West Bengal.

b. Inclusion criteria

i. 12 to 18 years old school going girls ii. Able to read, write and understand Bengali

iii. Informed consent from both the girl and accompanying teacher

c. Exclusion criteria

i. Poor comprehension of Bengali

ii. Disability hindering reading, writing or hearing

iii. Below average comprehension as assessed on clinical interview

iv. Unwilling to participate in study

Tools

A data sheet specially devised for this study containing certain personal data (like age, class etc) and Mental Health Awareness Questionnaire.

Mental Health Awareness Questionnaire: Psychiatrists, counsellors posted in Child and Adolescent guidance clinic, school teachers who watch child and adolescent population closely and a few persons who have adolescent children were approached by the research team, explained about the project and were requested to submit sample questions (in Bengali) pertaining to mental health issues of adolescents based on their day to day experience. Then, based on opinions of senior psychiatrists who attend to child and adolescent population in the OPD regularly, 20 questions from this list were selected and a questionnaire was constructed in Bengali. Then it was presented to the two counsellors posted in Child and Adolescent guidance clinic in the hospital, school teachers and parents of adolescents. Based on the consensus 13 questions were retained in the questionnaire. Out of these XIII questions, XII have multiple options to choose from and the last one is open ended. Some of the questions are case vignettes presented in simple words depicting certain situation, followed by choices. Out of these first XII questions, four (no. I,II,VIIandIX) are meant to assess knowledge about mental health issues in adolescence, while eight questions are kept observing their attitude towards some real-life examples related to mental health issues. The subjects are required to tick one choice for each of the first XII question that they think right. In the XIIIth question they are required to note down up to three ways they think that could help them feel happy.

For each of the knowledge questions one choice is correct and the frequency of correct answers is seen. For the attitude questions the frequency of the choices used by the subjects are observed. And for the open-ended question the ideas expressed by the subjects are noted.

\section{Conduction of the Study}

This pilot study was conducted after validating the questionnaire and after obtaining approval from the ethical committee (Ethical committee of Burdwan Medical College and Hospital). The purpose of the study was explained to the students and their accompanying 
teacher. Subjects who met the inclusion criteria were taken up in the study. The 13 item Bengali questionnaire were given to the girls, individually, after explaining the procedure to respond to it, before they attended the lecture. They were requested to complete the questionnaire on their own, unaided. Most of the girls returned the completed questionnaire within 30 minutes. After rejecting two data for multiple response in a few questions (from no. I to XII) and one data for not being returned, finally 107 samples were retained in this pilot study.

Validation of the Questionnaire: Face validity was determined through group discussion by experts

Test-retest reliability was seen by administering the questionnaire on a group of 20 girls of class VIII from a rural school nearby, twice, after a gap of 10 days.

\section{Result}

Table 1: Test re-test reliability.

\begin{tabular}{|c|c|c|c|}
\hline \multicolumn{3}{|c|}{ Questions } & kappa \\
\hline 1 & \multicolumn{2}{|c|}{ Adolescence is the period between: Youth and old age/Childhood and old age/Childhood and youth } & 0.783 \\
\hline 2 & \multicolumn{2}{|c|}{$\begin{array}{l}\text { Being listless, restless, losing temper and feeling guilt for no apparent reason during this period: Is usual/Should not } \\
\text { happen/Happens with some but not with others }\end{array}$} & 0.875 \\
\hline 3 & \multicolumn{2}{|c|}{$\begin{array}{l}\text { The problem mentioned in the previous question: Is serious/Nothing could be done about this/Pass away uneventfully } \\
\text { with help of friends and near and dear ones }\end{array}$} & 0.861 \\
\hline 4 & \multicolumn{2}{|c|}{$\begin{array}{l}\text { If someone starts having adolescence related problems: One should try to help him out/Avoid him/Avoid discussing the } \\
\text { topic with him }\end{array}$} & 0.630 \\
\hline 5 & \multicolumn{2}{|c|}{$\begin{array}{l}\text { Priyanka has consumed poison out of anger after being scolded at home. Her behaviour is: Abnormal/Normal /An ideal } \\
\text { way to teach her parents a lesson /An attempt to commit suicide }\end{array}$} & 0.697 \\
\hline 6 & \multicolumn{2}{|c|}{$\begin{array}{l}\text { After failure in exam your classmate Partha has been remaining absent in class for last } 3 \text { months. You have come to know } \\
\text { that he is depressed. You think: Since he has failed he shouldn't come to school/Depression is a mental illness that needs } \\
\text { to be treated/His absence is due to failure. He will become alright without any help. }\end{array}$} & 0.746 \\
\hline 7 & \multicolumn{2}{|c|}{$\begin{array}{l}\text { What, do you think, causes mental illness: Influence of spirit and supernatural elements/Bad karma of past life /Poor } \\
\text { hygiene/Heredity /Both environmental and hereditary causes }\end{array}$} & 0.596 \\
\hline 8 & \multicolumn{2}{|c|}{$\begin{array}{l}\text { Your best friend Uma has become withdrawn, remains absent in class frequently and has become irritable for quite some } \\
\text { time. You think: It's wise to avoid her/You should complain to teacher against Uma /She is doing this intentionally/She } \\
\text { needs help. You should come forward }\end{array}$} & 0.727 \\
\hline 9 & \multicolumn{2}{|c|}{$\begin{array}{l}\text { Reduced sleep and appetite, lack of concentration and excessive worries for a long time is a sign of: Physical illness/ } \\
\text { Mental illness/Is normal/Undisciplined life }\end{array}$} & 0.886 \\
\hline 10 & \multicolumn{2}{|c|}{$\begin{array}{l}\text { In case you are observing those symptoms mentioned in the previous question in yourself for last one month, you will } \\
\text { seek help from: Parents/Teachers/Friends/Doctor/Fortune-teller }\end{array}$} & 0.839 \\
\hline 11 & \multicolumn{2}{|c|}{$\begin{array}{l}\text { You are upset because of poor performance in exam, in spite of studying hard. You feel unable to speak out your distress. } \\
\text { You think you should: Hide your suffering from others/Seek help and support from friends /Should leave home/Should } \\
\text { try to calm down through relaxation }\end{array}$} & 0.914 \\
\hline 12 & \multicolumn{2}{|c|}{$\begin{array}{l}\text { How, would you like to describe your relationship with parents: They are understanding, and supportive/They are } \\
\text { supportive, though do not understand you/They do understand you, though do not cooperate/Always oppose you }\end{array}$} & 0.490 \\
\hline \multirow{8}{*}{13} & \multirow{8}{*}{ What, you think, are the ways to remain happy? } & Sports & 0.700 \\
\hline & & Health and Hygiene & 0.733 \\
\hline & & Food & 0.886 \\
\hline & & Discipline & 0.681 \\
\hline & & $\begin{array}{l}\text { Sharing, remaining Tension free, } \\
\text { Resilience }\end{array}$ & 0.886 \\
\hline & & Spending time with friends & 0.659 \\
\hline & & Others & 0.700 \\
\hline & & No response & 0.200 \\
\hline
\end{tabular}

Statistics: Statistical Package for Social Sciences (SPSS), 16th version, was used for the analysis of data.

Validation: Test-retest reliability was seen by kappa statistics.

Pilot Study: In the pilot study the distribution of age, class and religion in the sample was analyzed using descriptive statistics. For the knowledge-questions the frequency of correct response was seen by descriptive statistics. For the attitude-questions the frequency of using the choices in each question was noted through descriptive statistics. For the last question, i.e., the open ended one, subjects expressed several ideas about how to feel happy. So, the statements were grouped into eight broad categories, after reaching a consensus by experts. The frequency of responses in each category was seen by descriptive statistics. 
Test Re-Test Reliability: Eight out of twelve questions from I to XII had kappa value more than 0.7 indicating good test re-test reliability (Table 1). Questions II (0.875), 3 (0.861), 9 (0.886) and 11 (0.914) showed excellent test re-test reliability. Two questions had kappa value slightly less than 0.7 (questions 4 and 5), while the value was not satisfactory for questions VII (0.596) and 12 (0.490). In question no XIII most of the categories showed good to excellent test re-test reliability, though the category 'no response' had poor kappa value (0.200).

Table 2: Particulars of the sample.

\begin{tabular}{|c|c|c|}
\hline & & Frequency (\%) \\
\hline Age in years & 11 & $6(5.6)$ \\
\hline & 12 & $62(57.9)$ \\
\hline (Mean: $13.11 \pm 0.91)$ & 13 & $26(24.3)$ \\
\hline & 14 & $1(0.9)$ \\
\hline Class & 18 & $27(25.2)$ \\
\hline & 7 & $72(67.3)$ \\
\hline Religion & 8 & $8(7.5)$ \\
\hline & 9 & $74(69.2)$ \\
\hline
\end{tabular}

Table 3: Response to knowledge questions.

\begin{tabular}{|c|c|c|c|}
\hline \multicolumn{3}{|c|}{ Questions (Q) } & \multirow{2}{*}{$\begin{array}{c}\text { Frequency (\%) } \\
1(0.9)\end{array}$} \\
\hline \multirow{3}{*}{ Q1 } & \multirow{3}{*}{ Adolescence is the period between } & no response & \\
\hline & & correct & $54(50.5)$ \\
\hline & & incorrect & $52(48.6)$ \\
\hline \multirow{3}{*}{ Q2 } & \multirow{3}{*}{ Being listless, restless, losing temper and feeling guilt for no apparent reason during this period } & no response & $5(4.7)$ \\
\hline & & correct & $56(52.3)$ \\
\hline & & incorrect & $46(43.0)$ \\
\hline \multirow{3}{*}{ Q7 } & \multirow{3}{*}{ What, do you think causes mental illness } & no response & $5(4.7)$ \\
\hline & & correct & $54(50.5)$ \\
\hline & & incorrect & $48(44.9)$ \\
\hline \multirow{3}{*}{ Q9 } & \multirow{3}{*}{ Reduced sleep and appetite, lack of concentration and excessive worries for a long time is a sign of } & no response & $1(0.9)$ \\
\hline & & correct & $29(27.1)$ \\
\hline & & incorrect & $77(72.0)$ \\
\hline
\end{tabular}

Pilot Study: The mean age of our study population was found to be $13.11( \pm 0.91)$ years, majority of the girls were Hindu $(69.2 \%)$ and were studying in class VIII (67.3\%) (Table 2). While observing the response for the questions pertaining to knowledge (Table 3) it was found that there was more correct response in questions I (50.5\%), II (52.3\%) and VII (50.5\%), though majority gave incorrect responses to question 9 ( $72 \%$ ). Only $0.9 \%$ of the study population refrained from responding to each of the questions I and IX, while for each of the questions II and VII it was 4.7\%. Regarding the questions pertaining to attitude (Table 4), question no X was attempted by all the subjects. $13.1 \%$ of the girls did not respond to question no 6 , though this number was much less for rest of the questions (from $0.9 \%$ to $4.7 \%$ ). For most of the questions the subjects preferred one response over others, more so in questions IV (86\% choice 1 ) and XII (81.3\%). In the open-ended question most of the girls came out with ideas about how to feel happy (question XIII) (Table 5). Most of their ideas were related to categories 'sharing' (52.3\%), 'sports' (43\%) and 'food' (39.3\%). 9.3\% of them refrained from responding to this particular question. 
Table 4: Response to Attitude questions.

\begin{tabular}{|c|c|c|c|}
\hline \multicolumn{3}{|c|}{ Questions (Q) } & \multirow{2}{*}{$\begin{array}{c}\text { Frequency (\%) } \\
5(4.7)\end{array}$} \\
\hline \multirow{4}{*}{ Q3 } & \multirow{4}{*}{ Perception about adolescence crisis } & no response & \\
\hline & & choice 1 & $64(59.8)$ \\
\hline & & choice 2 & $17(15.9)$ \\
\hline & & choice 3 & $21(19.6)$ \\
\hline \multirow{4}{*}{ Q4 } & \multirow{4}{*}{ Intervention in adolescence crisis } & no response & $2(1.9)$ \\
\hline & & choice 1 & $92(86.0)$ \\
\hline & & choice 2 & $8(7.5)$ \\
\hline & & choice 3 & $5(4.7)$ \\
\hline \multirow{5}{*}{ Q5 } & \multirow{5}{*}{ Perception about self-harm behaviour } & no response & $3(2.8)$ \\
\hline & & choice 1 & $49(45.8)$ \\
\hline & & choice 2 & $7(6.5)$ \\
\hline & & choice 3 & $25(23.4)$ \\
\hline & & choice 4 & $23(21.5)$ \\
\hline \multirow{4}{*}{ Q6 } & \multirow{4}{*}{ Perception regarding adolescence depression } & no response & $14(13.1)$ \\
\hline & & choice 1 & $22(20.6)$ \\
\hline & & choice 2 & $61(57.0)$ \\
\hline & & choice 3 & $10(9.3)$ \\
\hline \multirow{5}{*}{ Q8 } & \multirow{5}{*}{ Attitude regarding adolescence depression } & no response & $1(0.9)$ \\
\hline & & choice 1 & $8(7.5)$ \\
\hline & & choice 2 & $21(19.6)$ \\
\hline & & choice 3 & $16(15.0)$ \\
\hline & & choice 4 & $61(57.0)$ \\
\hline \multirow{4}{*}{ Q10 } & \multirow{4}{*}{ Help seeking in mental illness } & choice 1 & $56(52.3)$ \\
\hline & & choice 2 & $19(17.8)$ \\
\hline & & choice 3 & $9(8.4)$ \\
\hline & & choice 4 & $23(21.5)$ \\
\hline \multirow{5}{*}{ Q11 } & \multirow{5}{*}{ Attitude regarding Stress management } & no response & $3(2.8)$ \\
\hline & & choice 1 & $18(16.8)$ \\
\hline & & choice 2 & $35(32.7)$ \\
\hline & & choice 3 & $1(0.9)$ \\
\hline & & choice 4 & $50(46.7)$ \\
\hline \multirow{5}{*}{ Q12 } & \multirow{5}{*}{ Attitude regarding parental relationship } & no response & $4(3.7)$ \\
\hline & & choice 1 & 87 (81.3) \\
\hline & & choice 2 & $5(4.7)$ \\
\hline & & choice 3 & $6(5.6)$ \\
\hline & & choice 4 & $5(4.7)$ \\
\hline
\end{tabular}


Table 5: Response to the Open-ended question (question no. 13).

\begin{tabular}{|c|c|c|}
\hline \multirow{5}{*}{ What, you think, are the ways to remain happy? } & Categories of responses & Frequency (\%) \\
\cline { 2 - 3 } & Sports & $46(43)$ \\
\cline { 2 - 3 } & Health and Hygiene & $29(27.1)$ \\
\cline { 2 - 3 } & Food & $42(39.3)$ \\
\cline { 2 - 3 } & Dharing, remaining Tension free, Resilience & $30(28)$ \\
\cline { 2 - 3 } & Spending time with friends & $56(52.3)$ \\
\cline { 2 - 3 } & Others & $29(27.1)$ \\
\cline { 2 - 3 } & No response & $34(31.8)$ \\
\cline { 2 - 3 } & & $10(9.3)$ \\
\hline
\end{tabular}

\section{Discussion}

Opinion from different quarter of persons and professionals who deal with adolescents regularly ensured that the questionnaire remains relevant to the target population, as well as, to the culture. Since knowledge and attitude about a problem influence a person's behavior towards it, questions pertaining to both domains were kept in the questionnaire. Having knowledge about adolescents' view of wellness and the ways to it might help us while dealing with their mental health issues [7]. So one open ended question was kept knowing about the ways, they think, could make them feel happy. A few questions were kept pertaining to stress, depression, anxiety and self-harm based on experience from previous studies $[2,3,6,7]$. Since majority of the school girls from this part of rural Bengal use Bengali as the primary language of communication the questionnaire was composed in Bengali. The fact that most of the questions had satisfactory to excellent kappa values demonstrates its reliability. Also, categorization of the responses to the openended question stands test of reliability. Poor kappa value of the 'no response' category (question XIII) might have resulted from the fact that some of the girls who refrained from responding to this question on first instance responded to it when presented the second time. Acceptability and feasibility were good as none of the subjects refused to respond to the questionnaire and most of them responded to almost all the questions unaided. From results it could be observed that though most of the girls answered the questions pertaining to what is meant by adolescence, mood swings during adolescence and cause of mental illness correctly, the difference between frequency of correct and incorrect responses was very less. Regarding question no IX where common depressive symptoms are elaborated, a little more than one fourth of the subjects could recognize those to be part of mental illness. Most of them thought these to be arising from reckless lifestyle or some physical illness. Coming to the questions related to attitude, in the question (no III) that raises the issue of mood swings, most of the girls think that the problem is serious, though next in number are those who think this could be overcome with help of close ones. While on direct question a good number of the subjects failed to recognize depressive symptoms as psychological in origin (question IX), on presenting case vignettes most of them readily identified the problem behaviors and came out with helping attitude (questions IV,V,VI and VIII). This seems to be in concert with previous observations where, despite a lack of knowledge about mental illness, most of participants expressed helping attitude. In the question pertaining to self-harm (question V) most of the girls thought this to be problem behavior, though quite a few of them think this to be a way of expressing grievances against parents [12]. It was also observed that most of them perceive their parents to be understanding and supportive and would seek help from them when faced with problems that they perceive as illness (questions $\mathrm{X}$ and XII). Though, while faced with academic setback most of the participants preferred to overcome the stressor themselves or to seek support from friends (question XI). This observation supports the findings of studies by where the subjects chose parents and friends as first point of contact to seek help [1,2,12].

Thus, it appears that adolescent girls, though have limited knowledge about adolescence, about mental health issues related to this period, they do identify when someone is in trouble and expressed readiness to help. They expressed reliance and grievances about their relationship with parents, and at the same time wanted to seek help from parents and friends when faced with some problem. This observation could be explained in the light of theories dealing with conflicts of adolescents [13]. This comfort zone with near and dear ones was further emphasized in their response about how to remain happy (question XIII). Most of them thought that sharing worries with friends, parents and others they feel close to; not worrying too much and resilience ('remaining calm in face of problems', 'mental strength' etc) could help them to be happy. Those observations highlight some of the aspects of positive mental health [2]. Though insignificant from statistical point of view, yet quite striking an observation was that two of the girls thought one can be happy if he/she can love others. A good number of opinions came in favour of games and sports as a way to remain happy. While a conspicuous number of the participants thought food can make them happy. This could be explained by the construct of 'Societal indicators of positive mental health' that mentions 'adequate food' along with some other factors [2]. 


\section{Conclusion}

This questionnaire appears to be a reliable tool to assess knowledge and attitude of our target population (adolescent school girls from rural background) regarding various common mental health issues related to adolescence. From the pilot study it could be concluded that acceptability and feasibility of this tool is satisfactory. Based on the responses it appears that there is a need to discuss various mental health issues related to adolescence to this population. This study exposed some the strengths of our adolescent population, like, an attitude to help and a sense of cohesion, as well as some of their concepts of remaining happy. The current study population did not include males, as well as, girls who were not going to school. Before generalizing the findings of this pilot study on adolescents larger and more inclusive studies need to be conducted.

\section{Adolescents' Mental Health Awareness Questionnaire}

School

Age (years)

Class

Please tick the correct answer of the following questions

I. Adolescence is the period between:

Youth and old age

Childhood and old age

Childhood and youth

II. Being listless, restless, losing temper and feeling guilt for no apparent reason during this period

Is usual

\section{Should not happen}

Happens with some but not with others

III. 3The problem mentioned in the previous question

Is serious 1

Nothing could be done about this

Pass away uneventfully with hel of friends and near and dear ones 2

IV. If someone starts having adolescence retaed problems

One should try to help him out 1

Avoid him

Avoid discussing the topic with him

V. Priyanka has consumed poison out of anger after being scoled at home. Her behaviour is

Abnormal 1
Normal

An ideal way to teach her parents a lesson 2

An attempt to commit suicide

VI. After failure in exam your classmate partha has been remaining absent in class for last 3 months. You have come to know that he is depressed. You think:

Since he has failed heshouldnt come to school 2

Depreesion is a mental illness that needs to be treted 1

His absence is ue to faile. He will become alright without any help.

VII. Wat, do you think causes mental illness

Influence of spirit and supernatural elements

Bad karma of past life

Poor hygiene

Heredity

Both environmental and hereditary causes

VIII. Your best friend Uma has become withdrawn, remaing absent in class frequently and has become irritable for quite some time. You think

It's wise to avoid her

You should complain to teacher against Uma. 2

She is doing this intentionally

She needs help. You should come forward 1

IX. Reduced sleep and appetite, lack of concentration and excessive worries for a long time is a sign of:

Physical illness

Mental illness

Is normal

Undisciplined life

$\mathrm{X}$. In case you are observing those symptoms mentioned in the previous question in yourself for last one month, you will seek help from:

Parents 1

Teachers

Friends

Doctor 4

Fortune-teller

XI. You are upset because of poor performance in exam, in spite of studying hard. You feel unable to speak out your distress. You 
think you should:

Hide your suffering from others

Seek help and support from friends 2

Should leave home

Should try to calm down through relaxation 4

XII. How, would you like to describe your relationship with parents:

They are understanding and supportive 1

They are supportive, though do not understand you

They do understand you, though do not cooperate

Always oppose you

XIII. What, you think, are the ways to remain happy?

\section{References}

1. Gopi Krishna B, Shakeer Kahn P, Ravi Prabhu G (2013) A Study on Help Seeking Behavior of their common problems among adolescent girls of government junior college in rural field practice area of SV Medical College. International Journal of Research \& Development of Health 1(1): 16-20.

2. Patel V, Flisher AJ, Nikapota A, Malhotra S (2008) Promoting child and adolescent mental health in low and middle-income countries. J Child Psychol Psychiatry 49(3): 313-334.

3. Hiremath K, Hunshal S, Gaonkar V (2012) Behavioral Problems among Early Adolescents. Karnataka Journal of Agricultural Sciences 21: 557560.

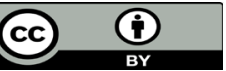

This work is licensed under Creative Commons Attribution 4.0 License

To Submit Your Article Click Here:

Submit Article
4. Zahn waxler C, Klimer dougan B, Slattery MJ (2000) Internalizing problems of childhood and adolescence: Prospects, pitfalls and progress in understanding the development of anxiety and depression. Dev Psychol 12(3): 443-466.

5. Alsaker FD (1996) Annotation: The impact of puberty. J Child Psychol Psychiatry 37(3): 249-258.

6. Garnefski N, Diekstra FW (1996) Perceived social support from family, school and peers: relationship with emotional and behavioural problems among adolescents. J Am Acad Child Adolesc Psychiatry 35(12): 16571664.

7. Hoven CW, Doan T, Musa GJ, Jaliashvili T, Duarte CS, et al. (2008) Worldwide child and adolescent mental health begins with awareness: a preliminary assessment in nine countries. WPA Awarness Task Force. Int Rev Psychiatry 20(3): 261-270.

8. Sherer R (2002) Mental health care in the developing world. Psychiatric Times XIX:1.

9. Miranda JJ, Patel V (2005) Achieving the millennium development goals: Does mental health play a role?. PLoS Medicine 2(10): 962-965.

10. Bijl RV, de Graaf R, Hiripi E, Kessler RC, Kohn R, et al. (2003) The prevalence of treated and untreated mental disorders in five countries. Health Aff 22(3): 122-133.

11. Rahman A, Mubbashar M, Harrington R, Gater R (2000) Developing child mental health services in developing countries. J Child Psychol Psychiatry 41(5): 539-546.

12. Yeap R, Low WY (2009) Mental health knowledge, attitude and helpseeking tendency: a Malaysian context. Singapore Med J 50(12): 11691176.

13. Smetana JG (1995) Parenting styles and conceptions of parental authority during adolescence. Child Dev 66(2): 299-316.

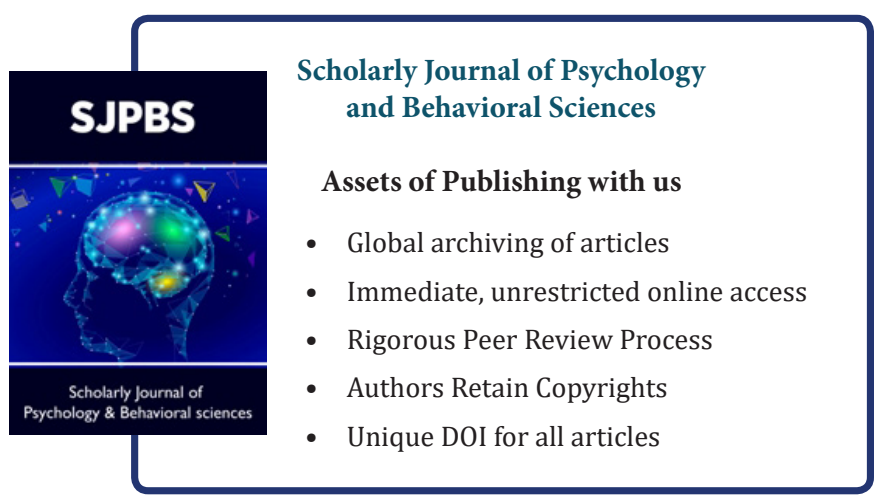

